\title{
Predictors of Adherence to Self-care Behaviour among Patients with Chronic Heart Failure Attending Jimma University Specialized Hospital Chronic Follow up Clinic, South West Ethiopia
}

\author{
Jemal Beker ${ }^{1}$, Tefera Belachew ${ }^{2}$, Altayeworke Mekonin ${ }^{2}$ and Endalew Hailu ${ }^{1^{*}}$ \\ ${ }^{1}$ Department of Nursing, College of Public Health and Medical Sciences, Jimma University, Ethiopia \\ ${ }^{2}$ Department of Population and Family Health, College of Public Health and Medical Sciences, Jimma University, Ethiopia
}

"Corresponding author: Endalew Hailu, Department of Population and Family Health, College of Public Health and Medical Sciences, Jimma University, Ethiopia. Tel: +25191048847; E-mail: EH-Endale.10@gmail.com

Received date: Aug 20, 2014; Accepted date: Oct 16, 2014; Published date: Oct 23, 2014

Copyright: @2014 Hailu E, et al. This is an open-access article distributed under the terms of the Creative Commons Attribution License, which permits unrestricted use, distribution, and reproduction in any medium, provided the original author and source are credited.

\begin{abstract}
Background: Appropriate self-care in patients with chronic illnesses such as Heart Failure (HF) is associated with prevention or early detection of health problems, better overall health and quality of life, improved clinical outcomes and reduced healthcare costs. Unfortunately, self-care among patients with heart failure is commonly poor, and patients have considerable difficulties performing self-care. There are no studies that documented the selfcare behaviour of cardiac patients in the study area. The objective of this study was to assess predictors of adherence to self-care behaviour among patient with chronic heart failure attending JUSH chronic follow up Clinic.
\end{abstract}

Methods: This study was conducted at JUSH chronic follow up clinic, from February 3 to March 30, 2012, using cross sectional design employing both quantitative and qualitative methods and a total of 255 outpatients with congested heart failure were completed the questionnaire. The sample size was calculated using a formula to estimate a single population proportion and the data was collected by administering pretested structured questionnaire for quantitative study and in depth interview guide for qualitative study.

Result: Out of the total 264 clients, 255 were included in the final analysis and giving a response rate of $96.6 \%$. Majority of the study subjects $151(59.2 \%)$ had poor adherence to self-care behaviour. The result of multivariable analysis also showed that knowledge of CHF, depression, duration of CHF, co-morbidity (hypertension and DM) and medication (being digitalized) were independent predictors of poorer adherence to self-care behaviour. Knowledgeable study subjects had 9.395 times more likely adherent to self-care when compared to study subjects that were illiterate, $[($ Adjusted OR $(95 \% \mathrm{Cl}$ of OR) $=9.395(4.014,21.991)]$ and CES-Depression scale also indicated significant association [(Adjusted OR $(95 \% \mathrm{Cl}$ of OR) $=2.142(1.168,3.928)]$ with adherence to self-care behaviour.

Conclusions and recommendations: The results of this study provided insights into self-care behaviour in patients with CHF. First, patients with CHF did not fully engage in self-care behaviour. Second, important factors including; depression, duration of $\mathrm{CHF}$, co-morbidity (hypertension and DM), medication (digitalize) and knowledge of CHF were identified as the top predictors of self-care behaviour. Therefore, nursing intervention programs regarding knowledge of $\mathrm{HF}$ is recommended for enhancing self-care and Self-care strategies should target especially patients with diabetes mellitus, depression and patient with less than one year duration of CHF.

Keywords: Heart failure; Self-care behaviour; congested heart failure; Adherence; Ethiopia

\section{Introduction}

According to World Health Organization (WHO) estimates, about $60 \%$ of deaths in the world are now caused by chronic non communicable diseases (WHO, 2005). The burden of chronic diseases remains stable in high income countries, while it is increasing in low and middle income countries as a result of (a) the epidemiological transition, (b) the rapid onset of traditional cardiovascular risk factors such as smoking and obesity, (c) the rapid rates of population aging, and (d) the process of migration from rural areas [1].

Cardiovascular disorder is the leading cause of death worldwide except in SSA, where it is surpassed by infectious and nutritional diseases. Whereas, about $80 \%$ of the global burden of CVD deaths occurs in low- and middle-income countries, and CVD is predicted to be the leading cause of death and disability worldwide by 2020 mainly because it will increase in low- and middle-income countries [1].

The final stage in almost any type of CVD is heart failure (HF) in which the heart muscle weakens and is unable to pump enough blood to the body and Heart failure (HF) is a common chronic illness associated with substantial morbidity and mortality, poor quality of life (QOL), and frequent hospitalizations, especially in adults over the age of 65 years in western country [1]. Although specific statistics are not available for every country, heart failure is believed to have reached epidemic proportions in both developed and developing countries [2].

As in any other developing countries, Ethiopia is also challenged by the growing magnitude of CNCDs which created a double burden on the population and the health system which is already hard hit by 
Citation: Beker J, Belachew T, Mekonin A, Hailu E (2014) Predictors of Adherence to Self-care Behaviour among Patients with Chronic Heart Failure Attending Jimma University Specialized Hospital Chronic Follow up Clinic, South West Ethiopia. J Cardiovasc Dis Diagn 2: 180. doi:10.4172/2329-9517.1000180

Page 2 of 8

communicable diseases. Available population based studies indicated high prevalence of CNCDs including hypertension, other cardiovascular diseases in both rural and urban parts of the country [3].

Heart failure is a chronic condition that requires a substantial amount of self-care. Appropriate self-care is associated with prevention or early detection of health problems; better overall health and quality of life; and, in patients with chronic illnesses such as Heart Failure (HF), improved clinical outcomes and reduced healthcare costs. Unfortunately, self-care among patients with heart failure is commonly poor, and patients have considerable difficulties performing self-care [4]. In many parts of Africa, including Ethiopia, the health care systems are designed to treat acute communicable diseases, rather than CNCDs including chronic heart failure. Patients with chronic heart failure have limited access to health care and even those under treatment are very likely to have uncontrolled disease conditions leading to high rate of complications and premature deaths. Now a day the problem of chronic diseases is gaining increasing attention in many developing countries. While many African countries have joined the force, Ethiopia lagged behind the regional initiative - a reflection of the low priority it has until recently accorded to the problem of chronic diseases including chronic heart failure [5].

So important is self-care for a patient with HF that the National Institutes of Health, currently has programs in place to promote selfcare research, but not at all gain attention in our country [6]. This study would be the baseline for further related studies for nursing and other professions. Farther more, the result of the study will be helpful for Local health planners and Local health departments for improving the health services for patients with HF. And also, helpful for Organizations working and supporting effective planning and implementation of health services for patients with HF.

\section{Methods and Subjects}

\section{The study setting}

Cross sectional study was conducted among cardiac follow up clinic in Jimma University Specialized Hospital, Jimma, Ethiopia. During the study period, there were 1,756 cardiac out patients registered for follow up and out of this, 656 were patients with CHF. The data were collected over a period of 30days (from February 3 to March 30, 2012)

\section{Population}

All randomly selecte6d adult patients with CHF attending in JUSH cardiac follow-up clinic were included by considering both inclusive and exclusive criteria. Based on this a study subjects that were on follow up and age $\geq 15$ years were included in the study however those who were with severe illness were excluded.

\section{Sample size}

Sample size was calculated assuming $0.5 \%$ of proportion (p) of cardiac patients with level of good adherence to self-care, 5\% marginal error (d) and confidence interval of $95 \%$.Based on this assumption, the sample size was calculated by single population proportion formula $\mathrm{n}=$ $((Z a / 2) 2 \times p(1-p)) / d 2$. This yield sample size of 384 . Since the source population was less than 10,000 the sample size was adjusted with correction formula and by considering $10 \%$ non-respondent's rate, the final sample size was 264 cardiac patients.

\section{Sampling technique}

Simple random sampling method was used to select patients and first sample frame of patients with $\mathrm{HF} \geq 15$ years was prepared according to the chronic follow up unit by their recording order. Then, study participants were selected randomly and interviewed.

For qualitative study Purposive sampling technique was used to gather in-depth information from key informants.

\section{Measurements}

\section{For quantitative study}

Self-care behaviour: Self-care behaviour was assessed using the modified European Heart Failure Self-Care Behavior Scale (EHFScBS) [7]. This was 11-item, self-administered questionnaire that covers information on the self-care behavior of patients with HF, such as daily weighting, fluid restriction, medication, and contacting health care providers when they experience increased weight gain. For each item, patients was rate their self-care behavior on a 5-point Like rt scale from5 ("I completely agree") to 1 ("I do not agree at all").The total score ranges from 11 to 55 and was calculated by summing the scores for each item. A higher score indicates good self-care behaviour. Reliability of the EHFScBS was pretested and it was good (Cronbach's alpha $=0.75$ ).

Predictors of self-care behaviour: Information on predictors of selfcare behaviour were collected from patients' medical records and completed questionnaires.

Clinical conditions: The following variables were assessed from the medical records: cause of HF, duration of HF, New York Heart Association (NYHA) functional class, previous hospitalizations with HF, and Co-morbidity such as anemia and diabetes mellitus. Patients were asked about their alcohol ("non-drinker," "less than 3times a week," or "more than 3 times a week") and smoking habits ("yes" or "no").

Cognitive and psychological status: To assess patients' knowledge about HF, an8-item scale was developed based on earlier studies Patients were presented with 8 statements about HF, such as "weight check is important to evaluate fluid retention," and were asked to respond "yes," "no," or "I do not know" to each statement $[7,8]$. Correct answers were scored 1; an incorrect answer or an answer of "I do not know" were scored 0. Scores for each item will be summed, giving a range of total scores from 0 to 8 . A higher score will indicate greater knowledge about HF. The content validity of the scale was confirmed by experts. In this study, internal consistency was assessed in terms of Cronbach's alpha and it was good (Cronbach's alpha= $0.72)$.

Symptoms of depression were measured using the modified Centre for Epidemiologic Studies-Depression Scale (CES-D) [9]. This is a 20item scale that measures depressive feelings and behaviours on a 4 point Like rt scale ranging from 0 ("rarely or none of the time") to 3 ("most or all of the time"). Scores for each item will be summed to give a range of total scores from 0 to 60 . A total score of more than 16 indicate the presence of depressive symptoms. Reliability of the CES-D was pretested and it was good (Cronbach's alpha=0.78).

Social attributes: Patients were asked about their living situation ("living with someone" or "living alone") and about whether they felt free to ask questions to the medical staff, with 5 levels ranging from 1 
Citation: Beker J, Belachew T, Mekonin A, Hailu E (2014) Predictors of Adherence to Self-care Behaviour among Patients with Chronic Heart Failure Attending Jimma University Specialized Hospital Chronic Follow up Clinic, South West Ethiopia. J Cardiovasc Dis Diagn 2: 180. doi:10.4172/2329-9517.1000180

Page 3 of 8

("I can ask questions without reserve") to 5 ("I cannot ask anything"). Reliability was pretested and it was good (Cronbach’s alpha=0.69).

\section{Qualitative study}

Data collection tools were adapted after review of relevant literatures. The questions and statements were grouped and arranged according to the particular objectives that they can address.

\section{Data collection procedure}

The quantitative data were collected using structured and pretested questioner by Five BSc Nurses through face to face interview. First, sample frame of study subjects were prepared according to the chronic follow up unit recording order. Then, study participants were selected randomly by their name and card number from the cardiac clinic patient registration book. Then, individual patient card was traced and interviewed to fill the data collection format.

For qualitative data, by using interview guide tool for in-depth interview, information was generated from the key informants. Besides Voice recorders and field-notes were used to capture the information

\section{Data analysis procedures}

The data were entered in to computer, cleared, explored, standardized and summarized using SPSS version 16.0. Descriptive analysis was used to describe the pattern of disease and Logistic regression was used to determine crude and adjusted OR. Bivariate analyses was carried out to assess association between the dependent and all the independent variables and to identify candidate for multivariate analysis. Then, multivariable analysis was performed to determine the independent predictors of the dependent variable. Statistical significance was measured by p-values $<0.05$ and adjusted odds ratio (AOR) with 95\% confidence interval (95\% CI). The qualitative data were analyzed first by transcribing the recorded data from Amharic and Affan Oromo in to English verbatim, and then the transcript was color-coded and grouped into thematic frameworks. Concepts extracted from themes were presented in narratives and triangulated with the quantitative results.

\section{Data quality assurance}

Pre-test was conducted on $5 \%$ of the respondents that did not participate in the main study and all necessary questionnaire modifications were made according to Ethiopian situation depending on the result of the analysis and the data was not included in the analysis. Internal consistency of the questionnaire was tested. The questionnaire was evaluated by one Internist and two BSc. Expert nurse's (Who had more than seven years of experience) in the field for wordings and content validity. Reliability of the questionnaire was good.

\section{Ethical considerations}

The study was approved and ethical clearance letters were written by Ethical Committee in College of Public Health and Medical Sciences, Jimma University and were brought to JUSH administrative office to undertake formal investigation. A consent sheet was prepared, translated in to local language and attached to the questionnaire in a separate page. In the consent sheet, it was stated that the purpose of this study was to assess predictors of adherence to self-care behaviour and that there is no way in which participating in the study can cause harm to the study subjects. Oral consent was obtained to ensure confidentiality, the consent sheet also provided information that there was no need to put their name on the survey questionnaire and that no individual response was reported. Statement about voluntary characteristic of their participation was also provided.

\section{Results}

A total of 255 study subjects were included in the final analyses giving a response rate of $96.6 \%$.The mean age $( \pm S D)$ of the study subjects was $48.76 \pm 18.76$ years, Approximately, equal proportions of males and females were involved in the study accounting for $130(51 \%)$ and 125(49\%), respectively. The three prevalent religions were: Muslim 175(68.6\%), Orthodox Christian 56(22\%) and Protestant 24(9.4\%). More than half of the total study subjects, $149(58.4 \%)$ were illiterate followed by those who attended primary school $38(14.9 \%)$. One hundred sixty six (45.5\%) of the study subjects were farmers.

\section{Cognitive and psychological attributes}

Out of the total study subjects asked to respond, about their level of knowledge about HF, more than three fourth of them 192(75.3\%) were not knowledgeable about HF. This finding was supported by qualitative finding as one 45 years old women key informant said "....The only thing that I monitored is the amount of salt that I used in the diet.”. Another 50yrs man also said “...Health professionals didn't say anything about the liquid. I just started to drink too much liquid which worsen the symptoms, then I was back in the hospital because my feet got swollen. I got too much liquid and too much sodium I asked them how do I know how much to take. They tried to tell me, but they really did not tell me how." The mean and SD level of knowledge score about CHF of study subject was $41.27 \pm 37.5$ with minimum and maximum response of 0 and 88 .

Out of the total study subjects on CES-Ds score, more than half of them had depressive symptom 142(55.7\%). This finding was supported by qualitative finding as one $38 \mathrm{yrs}$ old man key informant said "Nothing is important too much anymore...You know what you're doing [letting thing slide], you hate what you're doing, but you do it anyway." Another 40yrs old woman said "I started crying all the time because I was so mad ...Why I can't, just it is so simple, but yet I can't figure it out." The mean and SD CES-Depression scale score was $18.18 \pm 7.248$.

\section{Clinical condition related attributes}

Based on this study, 135(52.9\%) of the clients had clinical symptom of $\mathrm{CHF} \geq$ one year duration and $110(43.1 \%)$ of the study subjects had history of previous hospitalization once. Classification of heart failure by symptoms related to functional capacity (NYHA) showed that $145(56.9 \%)$ of study subjects were stage III CHF and more than half of them were taking ACEI/ARB, diuretics and digitalis medication $180(70.6 \%), 199(78 \%)$ and 136(53.3\%) respectively. In addition, study subjects were taking other medication like barbiturates, insulin, antibiotics, and analgesics. Patients with multiple Co-morbidities had accounted $158(62 \%)$. Hypertension and DM were a common comorbidity obtained from patients card $123(48.2 \%)$ and $93(36.5 \%)$, respectively (Table 1 ).

\begin{tabular}{|l|l|l|l|}
\hline Variables & Categories & Frequency & Percent \\
\hline $\begin{array}{l}\text { Previous } \\
\text { hospitalization }\end{array}$ & $\geq 1$ times hospital admission & 155 & 60.7 \\
\hline
\end{tabular}


Citation: Beker J, Belachew T, Mekonin A, Hailu E (2014) Predictors of Adherence to Self-care Behaviour among Patients with Chronic Heart Failure Attending Jimma University Specialized Hospital Chronic Follow up Clinic, South West Ethiopia. J Cardiovasc Dis Diagn 2: 180. doi:10.4172/2329-9517.1000180

Page 4 of 8

\begin{tabular}{|c|c|c|c|}
\hline & No hospital admission & 100 & 39.2 \\
\hline & Total & 255 & 100.0 \\
\hline \multirow{3}{*}{$\begin{array}{l}\text { Duration of heart } \\
\text { failure }\end{array}$} & $<1 \mathrm{yrs}$ & 120 & 47.1 \\
\hline & $>=1 \mathrm{yrs}$ & 135 & 52.9 \\
\hline & Total & 255 & 100.0 \\
\hline \multirow{5}{*}{$\begin{array}{l}\text { NYHA functional } \\
\text { class }\end{array}$} & 1 & 16 & 6.3 \\
\hline & ॥ & 66 & 25.9 \\
\hline & III & 145 & 56.9 \\
\hline & IV & 28 & 11.0 \\
\hline & Total & 255 & 100.0 \\
\hline \multirow[t]{6}{*}{ Types of medication } & ACE inhibitors/ARB & 180 & 70.6 \\
\hline & Beta-blocker & 136 & 53.3 \\
\hline & Digitalize & 64 & 25.1 \\
\hline & Diuretics & 199 & 78.0 \\
\hline & Ca channel blockers & 9 & 3.5 \\
\hline & Others & 171 & 67 \\
\hline \multirow[t]{7}{*}{ Co-morbidity } & DM & 93 & 36.5 \\
\hline & Hypertension & 123 & 48.2 \\
\hline & Acute Myocardial infection & 12 & 4.7 \\
\hline & Renal disease & 56 & 22.0 \\
\hline & Liver disease & 42 & 16.5 \\
\hline & Valvular heart disease & 26 & 10.2 \\
\hline & Others & 52 & 21.4 \\
\hline
\end{tabular}

three fourth of study subjects did not smoke cigarettes and did not drink alcohol 239 (93.7\%) and 239 (93.7\%) respectively (Table 2).

\begin{tabular}{|l|l|l|l|}
\hline Variables & Categories & Frequency & Percent \\
\hline Living arrangement & Living alone & 15 & 5.9 \\
\cline { 2 - 4 } & $\begin{array}{l}\text { Living with } \\
\text { someone }\end{array}$ & 240 & 94.1 \\
\cline { 2 - 4 } & Total & 255 & 100.0 \\
\hline \multirow{3}{*}{$\begin{array}{l}\text { Relationship with } \\
\text { medical staff }\end{array}$} & Poor & 237 & 92.9 \\
\cline { 2 - 4 } & Good & 18 & 7.1 \\
\cline { 2 - 4 } & Total & 255 & 100.0 \\
\hline $\begin{array}{c}\text { Dou smoke } \\
\text { cigarette? }\end{array}$ & No & 239 & 93.7 \\
\cline { 2 - 4 } & Yes & 16 & 6.3 \\
\cline { 2 - 4 } & Total & 255 & 100.0 \\
\hline Do you drink alcohol? & No & 239 & 93.7 \\
\cline { 2 - 4 } & Yes & 16 & 6.3 \\
\cline { 2 - 4 } & Total & 255 & 100.0 \\
\hline
\end{tabular}

Table 2: Social and behavioural attributes of clients with $\mathrm{CHF}$ attending JUSH chronic follow up Clinic, South West Ethiopia, February 3 to March 30, 2012GC.

\section{Level of adherence to self-care behaviour}

Figure one shows the percentage of level of adherence to self-care behaviour of study subjects .More than half of them 151(59.2\%) had poor adherence to self-care behaviour and good adherence to self-care behaviour accounts only $40.8 \%$.The mean $( \pm$ SD) of EHFScBS score was $31.74 \pm 5.85$ with minimum and maximum score of 16 and 44 respectively (Figure 1).

Table 1: Clinical symptoms and treatment practices of clients with CHF attending JUSH chronic follow up clinic, South West Ethiopia, February 3 to March 30, 2012 GC.

Majorities of study subjects used four or more than four type of medications $107(42 \%)$. This finding was supported by qualitative finding as a 50years old man said "I have been using 14pills a day ...Sometimes, I am embarrassed to go to the drug store." The mean and median of types of medication taken by study subjects were 3.28 and 3 with SD of 0.886 , the number of medications taken by study subject ranges from 1 to 6 .

\section{Social and behavioural attributes}

From total study subjects (255), more than half of them live with someone $240(94.1 \%)$. Mean and median value of relationship with medical staff to get necessary information about CHF were 37.25 and 40 with SD of \pm 17.3 , and the maximum and minimum value were 100 and 20. About $237(92.9 \%)$ of the total study subjects had poor relationships with medical staff. This finding was supported by qualitative finding as a 45 yrs old women said "...Someone telling me what to do? If he/she did not give me a medication, "Approximately

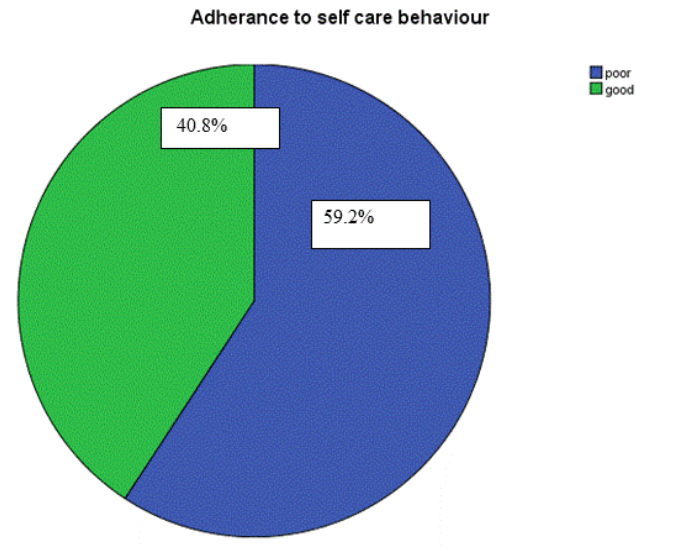

Figure 1: Level of adherence to EHFScBS among clients with CHF attending JUSH chronic follow up clinic, south west Ethiopia, February 3 to March 30, 2012 GC. 
Citation: Beker J, Belachew T, Mekonin A, Hailu E (2014) Predictors of Adherence to Self-care Behaviour among Patients with Chronic Heart Failure Attending Jimma University Specialized Hospital Chronic Follow up Clinic, South West Ethiopia. J Cardiovasc Dis Diagn 2: 180. doi:10.4172/2329-9517.1000180

Page 5 of 8

\section{Factors associated with adherence to self-care behaviour}

Binary logistic regression was made between outcome variable and factors that affect adherence to self-care behaviour. Some of the sociodemographic variables showed statistically significant association with adherence to self-care behaviour at $5 \%$ significance level.

Patients with age of $15-24$ years were $69.7 \%$ less likely adherent to self-care behaviour [(crude OR $(95 \% \mathrm{CI})=0.313(0.100,0.981)]$ and patients with age 45-54years were 2 times more likely adherent to selfcare behaviour [ $($ crude OR $(95 \%$ CI $)=2.091(1.09,3.995)]$. The finding of this study also showed that educational level had significant association with adherence to self-care behaviour. Clients with write and read only were 2.51 times more likely adhere to self-care [(crude OR $(95 \% \mathrm{CI})=2.51(1.067,5.908)]$ and study subject with primary school had 3.294 times more chance of adherence to self-care when compared to study subjects that were illiterates [(crude OR $(95 \% \mathrm{CI})=$ $3.294(2.116,4.747)]$.

On the other hand, residency, sex, ethnicity, occupation and income had no significant association with adherence to self-care behaviour at 95\% confidence level.

\section{Predictors of adherence to self-care behaviour}

Multivariable logistic regression analysis was fitted to determine predictors of adherence to self-care behaviour .Factors that showed significant association on bivariate analysis were interred together in multivariable analysis.

The result of the analysis showed that cognitive and psychological attributes, knowledge level and CES-Depression scale, had significant association at $95 \%$ confidence level. Knowledgeable study subjects were 9.395 times more likely adherent to self-care when compared to study subjects that were illiterate, [(Adjusted OR (95\% CI of OR) $=9.395(4.014,21.991)]$ and CES-Depression scale also indicates significant association [(Adjusted OR (95\% CI of OR) $=2.142(1.168$ 3.928)] with adherence to self-care behaviour of the study subjects .

Regarding clinical attributes, duration of CHF, Co-morbidity and medications remained in the final model. Patients with CHF with less than one year of duration were 0.554 times less likely adhered to selfcare behaviour when compared to patients with heart failure with duration of $\mathrm{CHF} \geq$ one years, [Adjusted OR $(95 \% \mathrm{CI})=0.554(0.045$, $0.198)]$, at $95 \%$ confidence level. Patients having co-morbidity of hypertension and DM had showed significant association in multivariate analysis. Patients not taking digitalize medication were 7 times more likely adherent to self-care behaviour when compared to those patient that had used digitalize medication [(Adjusted OR= $(95 \%$ CI of OR $)=6.919(2.966,16.138)]$.

Variables that showed significant association in bivariate analysis including; background variables (age and educational level), variables related of clinical attributes (NYHA functional classification and previous hospitalization) and medication (ACEI and ARI) had showed no significant association at this level in multivariate analysis at $95 \%$ confidence level (Table 3).

\begin{tabular}{|l|l|l|l|l|}
\hline VARIABLES & P-VALUE & ADJUSTED OR & $95.0 \%$ C.I. \\
\hline Knowledge level & \multicolumn{4}{|l|}{} \\
\hline Knowledgeable & $<0.001$ & 9.395 & 4.014 & 21.99 \\
\hline Fairly knowledgeable & 0.982 & 0.987 & 0.313 & 3.109 \\
\hline
\end{tabular}

\begin{tabular}{|c|c|c|c|c|}
\hline Not knowledgeable & & 1 & & \\
\hline \multicolumn{5}{|l|}{$\begin{array}{l}\text { CES-Depression } \\
\text { scale }\end{array}$} \\
\hline $\begin{array}{l}\text { Have no depression } \\
\text { symptom }\end{array}$ & 0.014 & 2.142 & 1.168 & 3.928 \\
\hline $\begin{array}{l}\text { Have a depression } \\
\text { symptom }\end{array}$ & & 1 & & \\
\hline \multicolumn{5}{|l|}{ Duration of CHF } \\
\hline$<1$ yrs & 0.041 & 0.351 & 0.045 & 0.198 \\
\hline$\geq 1 \mathrm{yrs}$ & & 1 & & \\
\hline \multicolumn{5}{|l|}{ Co-morbidity } \\
\hline \multicolumn{5}{|l|}{ Hypertension } \\
\hline No & $<0.001$ & 3.904 & 1.965 & 7.757 \\
\hline Yes & & 1 & & \\
\hline \multicolumn{5}{|l|}{ DM } \\
\hline Yes & 0.012 & 0.404 & 0.199 & 0.821 \\
\hline No & & 1 & & \\
\hline \multicolumn{5}{|l|}{ Medication } \\
\hline \multicolumn{5}{|l|}{ Digitalis } \\
\hline No & $<0.001$ & 6.919 & 2.966 & 16.14 \\
\hline Yes & & 1 & & \\
\hline
\end{tabular}

Table 3: Multivariable logistic regression Analysis of predictors of selfcare behaviour and clients adherence to self-care behaviour among patients with CHF attending JUSH chronic follow up clinic, South West Ethiopia, February 3 to March 30, 2012 GC.

\section{Discussion}

The results of this study provide insights into self-care behaviour in patients with CHF. First, patients with CHF did not fully engage in self-care behaviour such as daily weighing, eating a low sodium diet, getting regular physical activity and maintaining current body weight. Second, important factors including; depression, duration of HF, comorbidity (hypertension and DM), medication (being digitalized) and knowledge of CHF were identified as the top predictors of self-care behaviour that may contribute for the improvement. These insights provide important information for developing effective interventions to improve self-care behaviour in patients with CHF in JUSH chronic follow up clinic.

Overall, the finding of this study demonstrates that more than half of study subject with CHF 151(59.2\%) had poor adherence to self-care behaviour. This finding is consistent with other studies, used the same self-care measuring instruments (EHFScBS), among patient with $\mathrm{CHF}$ in Vietnam Thai Nguyen General Hospital which was 50.9\% [10].

The mean age of the study subjects in this study were 48.7 years similar with the finding in south western Nigeria which was 56.01 years [11].Increasing age ( $\geq 55 \mathrm{yrs}$ ) was associated with relatively better CHF self-care behaviour at bivariate analysis in this study. Prior studies of age and self-care have yielded contradictory results. In a 
study by Levanthal and Prohaska, the elderly, defined as those 60 years and older, tended to attribute symptoms such as fatigue and weakness to normal aging[12]. In persons with $\mathrm{CHF}$, attributing fatigue and weakness to age rather than fluid overload would be evidence of poor self-care. Conversely, Spitzer et al, found that older patients were more likely to depend on themselves for solutions to their health problems and to feel greater satisfaction with their solution, provided the severity of symptoms was not too great[13]. Further research is needed to explain why increasing age was associated with better CHF self-care and whether symptom severity interacts with age as a predictor of CHF self-care.

Gender is another factor rarely studied as a contributor to CHF selfcare, but the results of this study indicates that gender was not important predictor of self-care behaviour, Contrary to the results of Riegeland Gocka which found that females reported taking better care of themselves than males [14]. However, Lee et al. found that older CHF patients were associated with worse self-care, especially response to symptoms which occur for both men and women [15]. Thus, it may be explained why gender had no relation to self-care behaviour.

This study also revealed that most of patients 149(58.4\%) were illiterate; this finding was supported by Nguyen N.H., Pornchai J. et al. study that most of patients $(66.2 \%)$ had low educational level [10]. Bivariate logistic regression finding showed association and is consistent with that of other investigators. In an early comprehensive review of the compliance literature, Macabasco A. and colleagues found a positive association between education and compliance with self-care behaviour Participants with adequate literacy reported higher self-care behaviour scores than those with low literacy (mean score 5.3 vs. 4.2, adjusted difference 0.59 [CI 0.96, 0.22]) [16]. Overall, Bettereducated persons may be more likely to engage in self-care than those who are poorly educated [16].

It is important that the relationship between education and self-care not be interpreted as suggesting that a person who is poorly educated cannot learn self-care. Self-care is a process that can be taught. It takes time to learn the process, and the poorly educated may simply need more time to learn self-care than do those who are better educated.

One of the major finding of this study was knowledge is the potential predictor of self-care behaviour. Majority of Patients in this study had low levels of knowledge 192(75.3\%) about the specifics of HF self-care, which suggests the need for creative approaches to provide information to patients with this condition. Despite the low levels, knowledge was significantly associated with self-care behaviour $(\mathrm{p}<0.001)$, highlighting the importance of any level of CHF specific knowledge. This finding was supported by studies among patients with $\mathrm{CHF}$ in Vietnam Thai Nguyen General Hospital, Knowledge of CHF correlates with self-care behaviour $(r=0.66, p<0.01)(20)$.This finding is also in keeping with Orem's theory that proposes that knowledge is a power that enables self-care; it must be specific and organized around the meeting of known self-care requisites. In this study, the impact of knowledge on self-care behaviour among patients with HF is clear. Even though it is recognized that knowledge is necessary for self-care, it is not a sufficient condition. To help patients meet their requirements for self-care, greater attention needs to be given to understanding the inhibiting and promoting effects of BCFs on selfcare performance.

Recently, the role of depression in patients with HF has been underscored [15].This finding showed high percentage 142(55.7\%) of patients with depressive symptoms. This finding was in keeping with
Martje H.L and Vander Wal1, which was (41\%). This finding also indicates patients with no depression symptom had more chance for adherence to self-care behaviour as compared to study subjects that had a depression symptom [ (crude OR $=(95 \%$ of $\mathrm{CI})=1.684(1.017$, 2.790)] [8].This finding was supported by Riegel and Gocka, Patients with CHF with minor depression reported significantly lower levels of self-care than those patients with CHF with non depressive symptom $(\mathrm{P}=0.001)$ [14].

The other finding of this study was that patients with more severe symptoms (NYHA stage III \& IV) more likely adhere to self-care behaviour in bivariate analysis. This finding was supported by Chriss et al, which showed that patients with more severe HF tended to have higher adherence to self-care behaviour [17]. As functional status worsened, understanding of the importance of various signs and symptoms of HF improved. In addition, a person with more severe disease may be more motivated to learn and engage in self-care with the intention of preventing disease exacerbation than a person with mild disease who fails to see the importance of attending to self-care. This finding was different from that of Nagy and Wolfe that severity of symptoms negatively affects self-care [18].The influence of severity of symptoms on self-care requires further exploration, especially in how it relates to a person's ability and motivation to learn self-care.

In this study, subjects with less duration of heart failure $(<1 \mathrm{yrs})$ were less likely adherent to self-care behaviour when compared to patients with more duration of CHF ( $\geq 1 \mathrm{yrs}$ ) and it is an important predictor of self-care behaviour. This finding was supported by Carlson et al., which showed that patients newly diagnosed with HF, experienced greater difficulty in recognizing their HF symptoms; therefore, the duration of HF was positively related to adherence to self-care .This may be due to experience which produced better understanding of the importance of self-care in a change from baseline health status.

Virtually, all individuals with HF have other illnesses. In this study, patients with hypertension and DM Co-morbidity had association with self-care behaviour. A study by Moses $\mathrm{K}$ and Olufunke O., On a ten-year retrospective cohort review of the $202 \mathrm{CHF}$ case notes from the Medical Records in South western Nigeria found that $34.7 \%$ of the patients had diabetes mellitus, $37.6 \%$ were hypertensive, $5 \%$ had vascular disease, $8.9 \%$ had kidney disease, $5.9 \%$ had liver disease, $6.4 \%$ had myocardial infarction and $4.5 \%$ had corpulmonale [11].The presence of co morbidities contributes to difficulties in self-care in four major areas: Medication taking, dietary adherence, symptom monitoring, and decision making about how to manage multiple conditions [19].

Surprisingly, living arrangement (family support) was not a significant predictor of adherence to self-care behaviour, based on the main or direct effect hypothesis of family support. The main effect hypothesis states that support enhances health irrespective of stress level. That is, support is likely one of the mechanisms that has a direct impact on changing health-promoting behaviour and outcomes. Several studies of persons with HF have suggested that social support should be a significant predictor of HF self-care. For example, Happ et al found that the absence of strong family support contributed to poor treatment adherence [20]. In the study of Artinian et al, it was showed that patients who lived alone were less likely to ask for help if HF worsened than other patients [21]. In a recent study, Dunbar and colleagues found HF self-care, especially diet adherence, to be better in patients randomized to a family-centred educational intervention and 
Citation: Beker J, Belachew T, Mekonin A, Hailu E (2014) Predictors of Adherence to Self-care Behaviour among Patients with Chronic Heart Failure Attending Jimma University Specialized Hospital Chronic Follow up Clinic, South West Ethiopia. J Cardiovasc Dis Diagn 2: 180. doi:10.4172/2329-9517.1000180

Page 7 of 8

also they found that support from family and friends was an important influence on adherence to self-care[22].

Generally, in this study, depression, duration of HF, co-morbidity (hypertension and DM), medication (being digitalized) and knowledge of CHF were identified as the top predictors of self-care behaviour. A study in Vietnam Thai Nguyen General Hospital showed that; Knowledge of HF and social support $(r=0.66$, and $r=0.53, p<0.01$, respectively) were independent predictors [10]. A study in Japan also revealed that $\mathrm{DM}$ and being employed were independent predictors of poorer adherence to self-care. Behaviour $(\mathrm{P}=0.03, \mathrm{P}=0.02$, respectively) [23]. Martje H.L. \& van der Wal also found that; Knowledge (OR 1/4 5.67; CI 2.87-11.19), duration of CHF (AOR 1.78; CI 1.18-2.69), and depressive symptoms (AOR 0.53; CI 0.35-0.78) were independent predictors of self-care behaviour [24].

\section{Limitations of the Study}

First, the patient population was relatively small and the patients were limited to outpatients at a single hospital. Self-care behaviour might vary under different circumstances or in different groups of patients. Self-care behaviour was measured only by self-reporting (Recall bias might have occurred). Second, scarcity of reference materials on specific topic which this study fails to benefit from previous experiences and compare our result. Third, because of the cross-sectional nature of this study, cause-effect relationship was not tested.

\section{Conclusion}

Heart failure self-care behaviours are essential for patients with HF to master for achieving the best possible health outcomes. The important conclusions from the data reported in this study are patients with CHF did not fully engage in self-care behaviour such as daily weighing, eating a low sodium diet, getting regular physical activity and maintaining current body weight. More than half of study subjects with CHF 151(59.2\%) had poor adherence to self-care behaviour.

Moreover, this study found out that important modifiable factors knowledge of CHF, and also other factors including; depression, duration of $\mathrm{CHF}$, co-morbidity (hypertension and DM) and medication (digitalize) were identified as independent predictors of poorer adherence to self-care behaviour but living arrangement (living with someone) was not a significant predictor of poorer adherence to self-care behaviour. Nurses working in JUSH chronic follow up clinic should develop assessment plans to identify patients with HF who have poor self-care behaviours. Nursing intervention programs in JUSH chronic follow up clinic regarding knowledge of $\mathrm{HF}$ is recommended for enhancing self-care behaviours of patient with HF.

Self-care strategies should target especially patients with diabetes mellitus, depression and patient with less than one year duration of $\mathrm{CHF}$, who are more likely to have poorer adherence. As patients with more depressive symptoms showed poorer adherence to self-care behaviour in this study, extra attention should be paid to those patients. Therefore, it is important for health care providers to learn to recognize depressive symptoms in HF patient and treat depressed patients according to existing psychiatric guidelines. A further study in large scales on many hospitals is recommended on predictors of adherence to self-care behaviour among PWHF as part of health care quality assurance.

\section{Competing Interests}

The authors declared that they have no competing interest

\section{Authors' Contribution}

JB, TB, AM conceived the study. JB,TB,AM and EH were involved in the design ,filed work, data analysis and interpretation ,reporting writing and manuscript preparation in addition $\mathrm{EH}$ drafted the manuscript .all authors reviewed, read and approved the final version of the manuscript

\section{Acknowledgement}

We acknowledge Jimma University for funding this study. We are also thankful to the study participants for their voluntary participation

\section{References}

1. World Health Organization (2011) Global health risks: mortality and burden of disease attributable to selected major risks.

2. Roger VL, Go AS, Lloyd-Jones DM, Adams RJ, Berry JD, et al. (2011) Heart disease and stroke statistics--2011 update: a report from the American Heart Association. Behaviour Circulation 123: e18-e209.

3. Akinboboye O, Idris O, Akinboboye O, Akinkugbe O (2003) Trends in coronary artery disease and associated risk factors in sub-Saharan Africans. BehaviourJ Hum Hypertens 17: 381-387.

4. Shafazand M, Schaufelberger M, Lappas G, Swedberg K, Rosengren A (2009) Survival trends in men and women with heart failure of ischaemic and non-ischaemic origin: data for the period 1987-2003 from the Swedish Hospital Discharge Registry. Behaviour Eur Heart J 30: 671-678.

5. Tesfay $\mathrm{F}(2008)$ Epidemiology of cardiovascular disease risk factors in Ethiopia: The urban and rural gradient. UUMD 1151: 0346-6612.

6. National Institute of Nursing Research (2012) Nursing science centres in self-management or end-of-life research: building research teams for the future.

7. Ni H, Nauman D, Burgess D, Wise K, Crispell K, et al. (1999) Factors influencing knowledge of and adherence to self-care among patients with heart failure. BehaviourArch Intern Med 159: 1613-1619.

8. van der Wal MH, Jaarsma T, Moser DK, van Veldhuisen DJ (2005) Development and testing of the Dutch Heart Failure Knowledge Scale. BehaviourEur J CardiovascNurs 4: 273-277.

9. Radloff LS (1977) The CES-D scale: a self-report depression scale for research in the general population. ApplPsycholMeas1:385-401

10. Huyen NN, PornchaiJullamate, and WareeKangchai (2011) Factors related to Self-care Behaviors among Older Adults with Heart Failure in Thai Nguyen General Hospital, Vietnam; J. Adolesc Health103:366-371

11. Kayode M. And Olufunke O (2010) A ten year study of management of chronic heart failure in a tertiary hospital in the South west Nigeria. Wiloloud journal 4: 18-27.

12. Leventhal EA, Prohaska TR (1986) Age, symptom interpretation, and health behavior. BehaviourJ Am GeriatrSoc 34: 185-191.

13. Spitzer A, Bar-Tal Y, Ziv L (1996) The moderating effect of age on selfcare. BehaviourWest J Nurs Res 18: 136-148.

14. Riegel B, Gocka I (1995) Gender differences in adjustment to acute myocardial infarction. BehaviourHeart Lung 24: 457-466.

15. Lee CS, Riegel B, Driscoll A, Suwanno J, Moser DK, et al. (2009) Gender differences in heart failure self-care: a multinational cross-sectional study. BehaviourInt J Nurs Stud 46: 1485-1495.

16. Macabasco-O'Connell A, DeWalt DA, Broucksou KA, Hawk V, Baker DW, et al. (2011) Relationship between literacy, knowledge, self-care behaviors, and heart failure-related quality of life among patients with heart failure. BehaviourJ Gen Intern Med 26: 979-986. 
Citation: Beker J, Belachew T, Mekonin A, Hailu E (2014) Predictors of Adherence to Self-care Behaviour among Patients with Chronic Heart Failure Attending Jimma University Specialized Hospital Chronic Follow up Clinic, South West Ethiopia. J Cardiovasc Dis Diagn 2: 180. doi:10.4172/2329-9517.1000180

Page 8 of 8

17. Chriss PM, Sheposh J, Carlson B, Riegel B (2004) Predictors of successful heart failure self-care maintenance in the first three months after hospitalization. BehaviourHeart Lung 33: 345-353.

18. Nagy VT, Wolfe GR (1984) Cognitive predictors of compliance in chronic disease patients. BehaviourMed Care 22: 912-921.

19. Dickson VV, McCauley LA, Riegel B (2008) Work-heart balance: the influence of biobehavioral variables on self-care among employees with heart failure. BehaviourAAOHN J 56: 63-73.

20. Happ MB, Naylor MD, Roe-Prior P (1997) Factors contributing to rehospitalization of elderly patients with heart failure. BehaviourJCardiovascNurs 11: 75-84.

21. Artinian NT, Magnan M, Sloan M, Lange MP (2002) Self-care behaviors among patients with heart failure. BehaviourHeart Lung 31: 161-172.
22. Dunbar SB, Clark PC, Deaton C, De A, Smith AL (2003) The effect of a family-focused intervention on self-management of diet, medicationtaking and activity after six months. Paper presented at: Heart Failure Society of American.

23. van der Wal MH, Jaarsma T, van Veldhuisen DJ (2005) Non-compliance in patients with heart failure; how can we manage it? Behaviour Eur J Heart Fail 7: 5-17.

24. van der Wal MH, Jaarsma T, Moser DK, Veeger NJ, van Gilst WH, et al. (2006) Compliance in heart failure patients: the importance of knowledge and beliefs. BehaviourEur Heart J 27: 434-440. 